\title{
Monoamine metabolite concentrations in lumbar cerebrospinal fluid of patients with histologically verified Alzheimer's dementia
}

\author{
ALAN M PALMER,${ }^{*}$ NEIL R SIMS,${ }^{*}$ DAVID M BOWEN,${ }^{*}$ DAVID NEARY,$\dagger$ \\ JORMA PALO, $\ddagger$ JUHANI WIKSTROM, $\ddagger$ ALAN N DAVISON*
}

From Miriam Marks Department of Neurochemistry, Institute of Neurology, London, ${ }^{*}$ the Department of Neurology, Manchester Royal Infirmary, Manchester, $\dagger$ the Department of Neurology, University of Helsinki, Finland, $\ddagger$ and the National Hospital for Nervous Diseases, London, UK

SUMMARY Concentrations of 3-methoxy-4-hydroxyphenylglycol (MHPG), 5-hydroxy indoleacetic acid (5-HIAA) and homovanillic acid (HVA) were determined in lumbar cerebrospinal fluid (CSF) from control subjects and patients of both presenile and senile age with histologically verified Alzheimer's dementia. CSF HVA increased with age in control but not in Alzheimer patients. HVA and 5-HIAA in the CSF of presenile Alzheimer patients was lower than that of age matched control subjects.

Alzheimer's dementia, now regarded as a disease of senium as well as pre-senium, presents as an impairment of higher mental function' and is characterised histologically by large numbers of neuritic (senile) plaques and neurofibrillary tangles in the neocortex and hippocampus. ${ }^{2}$ A further characteristic is a substantial decline of presynaptic cholinergic function in the neocortex. ${ }^{3}$ Although the involvement of other ineurotransmitter systems is not well established, evidence implicating both a cortical ${ }^{4-8}$ and a subcortical ${ }^{9-11}$ dysfunction of monoamine neurotransmitter systems has emerged.

Indirect assessment of cerebral monoamine function in memory disorders by analysis of metabolites in cerebrospinal fluid (CSF) has identified a specific alteration in Korsakoff s psychosis. ${ }^{12}$ Similar studies in Alzheimer's dementia have yielded conflicting results, with some authors reporting reduced concentrations of 5-hydroxyindoleacetic acid (5HIAA) ${ }^{13}$ and homovanillic acid (HVA) ${ }^{13-18}$ while others ${ }^{19-21}$ find no change. It seems likely that these discrepancies are partly due to differences in diag-

Address for reprint requests: AM Palmer, Department of Neurochemistry, Institute of Neurology, 33 John's Mews, London WC1N 2NS.

Received 25 October 1983. Accepted 5 November 1983.

NR Sims is now at Dementia Research Service, Burke Rehabilitation Center, Cornell University Medical School, White Plains, NY, USA. nostic criteria since the diagnosis of Alzheimer's dementia was not verified by neurohistological examination in any of these studies.

The present investigation compared the concentrations of 3-methoxy-4-hydroxyphenylglycol (MHPG), 5-HIAA and HVA in the CSF of a group of histologically verified presenile Alzheimer patients with that of a group of age-matched controls, apparently free of neurological disease. Both groups have also been compared with a small group of histologically confirmed Alzheimer patients of senile age. A preliminary report of part of this study has previously been published. ${ }^{22}$

\section{Materials and methods}

CSF was analysed from 34 patients with Alzheimer's dementia, 25 (10 male, 15 female) were of presenile age (less than 70 years) and nine (four male, five female) were of senile age (at least 70 years). All patients had a clinical diagnosis of Alzheimer's dementia. Brain tissue was examined at diagnostic craniotomy in 12 and at necropsy in 22 patients. Plaque and tangle formation was of an intensity consistent with a diagnosis of Alzheimer's dementia in all cases. All the biopsy-verified patients were drug free at the time of lumbar puncture, whereas 14 of the necropsy verified patients were undergoing treatment with phenothiazines and/or butyrophenones. The control group consisted of 38 patients undergoing investigation for a variety of peripheral and spinal cord complaints. Only patients over 50 years of age (10 male, 15 female) were used to compare with Alzheimer patients. Patients with evidence 
of neurological disease or disc lesions were excluded.

MHPG, 5-HIAA and HVA standards (Sigma Chemical Co, Poole, UK) were stored as $100 \mu \mathrm{g} / \mathrm{ml}$ aliquots at $-70^{\circ} \mathrm{C}$ and diluted appropriately before use. CSF was removed from the lumbar subarachnoid space following overnight fast and frozen at $-70^{\circ} \mathrm{C}$ until analysis. Samples were filtered using $15 \mu \mathrm{M}$ microfilters (Bioanalytical Systems Inc, West Lafayette, USA) and separated by reverse phase chromatography using a $4.6 \times 150 \mathrm{~mm} \mathrm{C}_{18}, 5 \mu \mathrm{M}$ column protected by a $4.6 \times 60 \mathrm{~mm}$ pre-column (Ultrasphere, Altex Scientific Inc, USA). The mobile phase comprised: $94 \% 200 \mathrm{mM} \mathrm{Na}$ acetate/acetic acid, $50 \mu \mathrm{M}$ ethylenediaminetetracetic acid, pH 4.96 (all Analar grade chemicals from British Drug Houses); 6\% HPLC grade methanol (Rathburn Chemicals Ltd, Walkerburn, UK). Prior to use, the mobile phase was passed, under vacuum, through a $0.5 \mu \mathrm{M}$ filter (FHUP 04700, Millipore Ltd, London). A reciprocating pump (11 VA, Altex) maintained a flow rate of $1.3 \mathrm{ml} / \mathrm{min}$. An electrochemical detector (LC4A, Bioanalytical Systems Inc) together with a glassy carbon electrode (TL5, Bioanalytical Systems Inc) were used at a potential of $750 \mathrm{mV}$. Preliminary studies identified MHPG, 5-HIAA and HVA peaks in CSF by (a) spiking with a small volume of an appropriate concentration of standard and (b) comparing the electrode response profile with varying potential in CSF with that of standards. Peaks were subsequently identified by comparing retention times in CSF with that of a standard solution. CSF monoamine metabolite concentrations were determined by comparing the peak heights of standards with duplicate $100 \mu \mathrm{l}$ injections of CSF. Electrode response increased linearly from 0 to $100 \mathrm{ng} / \mathrm{ml}$ and the sensitivity (defined as amount detectable when signal/noise $=2$ ) was calculated to be $80 \mathrm{pg}$ for MHPG and 5-HIAA and $140 \mathrm{pg}$ for HVA. Interfering peaks obscured MHPG in one and 5-HIAA in three cases. Statistical differences between groups was assessed by a two-tailed Student's $t$ test. Correlations were examined using the Pearson product moment.

\section{Results}

CSF concentrations of all three metabolites were independent of patient gender. Alzheimer patients undergoing neuroleptic drug treatment had 5-HIAA values $39 \%$ higher than drug free Alzheimer patients of similar age. MHPG and HVA were not significantly affected by drug therapy (table 1$)$. The content of HVA in the CSF correlated with age in control $(\mathrm{r}=0.39, \mathrm{n}=38, \mathrm{p}<0.02$; fig)

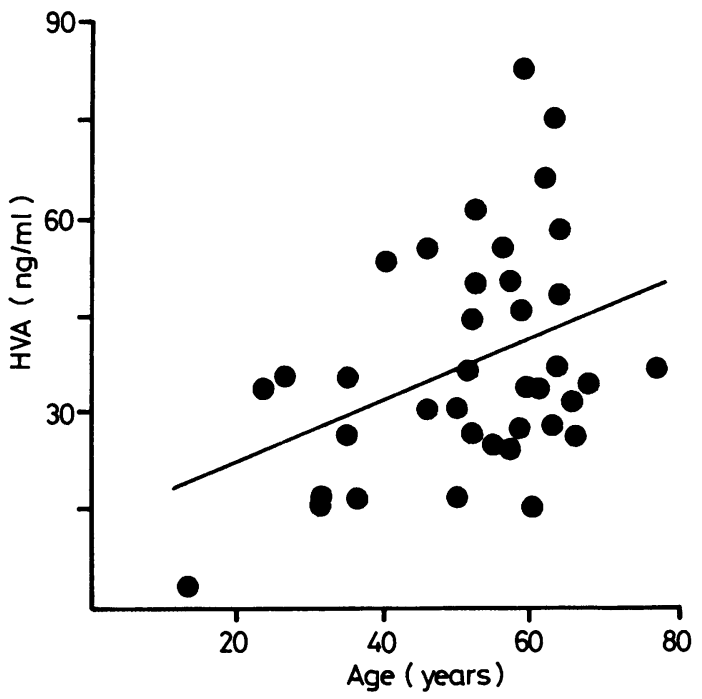

Fig Correlation between homovanillic acid concentration in the CSF of control patients and age $(n=38, r=0.39$, $p<0.02$ ).

but not Alzheimer $(r=0.09, n=34)$ patients. Age did not correlate with either MHPG or 5-HIAA.

Table 2 shows that in comparison with agematched control subjects, the HVA content in the CSF of presenile Alzheimer patients was reduced by $28 \%$ and that the 5-HIAA content of drug-free Alzheimer patients was reduced by $25 \%$. MHPG was unchanged. 5-HIAA and MHPG were unaltered in senile Alzheimer patients. The elevation of HVA content with age in control subjects invalidates direct comparison between mean values for senile Alzheimer patients and the younger control subjects. Extrapolation from the figure, however, suggests that $50 \mathrm{ng} / \mathrm{ml}$ is an appropriate control value. This indicates that homovanillic acid in the CSF of Alzheimer patients of senile age is reduced by $42 \%$.

Table 1 Effect of neurotropic drug treatment on monoamine metabolite concentrations in the CSF of patients with Alzheimer's dementia. Results are mean $\pm S D$, with number of patients in parenthesis

\begin{tabular}{lllll}
\hline & Age $(y r)$ & \multicolumn{3}{c}{ Concentration in CSF (ng/ml) } \\
\cline { 3 - 5 } & & HVA & $5-H I A A$ & MHPG \\
\hline Drug treated & $64 \pm 4(13)$ & $35 \cdot 5 \pm 24 \cdot 6(13)$ & $21 \cdot 2 \pm 6 \cdot 6(11){ }^{*}$ & $7 \cdot 2 \pm 1 \cdot 4(13)$ \\
Drug free & $69 \pm 12(21)$ & $28 \cdot 1 \pm 13 \cdot 4(21)$ & $15 \cdot 3 \pm 5 \cdot 7(20)^{*}$ & $8 \cdot 3 \pm 2 \cdot 4(21)$ \\
\hline
\end{tabular}

${ }^{*} \mathrm{p}<0.05$, Student's $t$ test. 
Table 2 Concentration of MHPG, 5-HIAA and HVA in the CSF of histologically-verified presenile and senile Alzheimer patients compared to a group of control subjects. There is no selection of data except for 5-HIAA where only results for patients free from neuroleptic treatment are included. Results are mean $\pm 1 S D$ with number of patients in parenthesis.

\begin{tabular}{lllll}
\hline & Age $(y r)$ & \multicolumn{3}{c}{ Concentration in CSF (ng/ml) } \\
\cline { 3 - 5 } & & HVA & $5-H I A A$ & MHPG \\
\hline Controls & $60 \pm 6(25)$ & $42 \cdot 3 \pm 17 \cdot 1(25)$ & $21 \cdot 4 \pm 8 \cdot 4(23)$ & $7 \cdot 2 \pm 2 \cdot 3(25)$ \\
Alzheimer's dementia (presenile) & $63 \pm 5(25)$ & $30 \cdot 5 \pm 16 \cdot 1(25) \dagger$ & $16 \cdot 0 \pm 6 \cdot 0(16) *$ & $8 \cdot 3 \pm 2 \cdot 2(25)$ \\
Alzheimer's dementia (senile) & $79 \pm 11(9) \ddagger$ & $29 \cdot 1 \pm 17 \cdot 8(9) \S$ & $13 \cdot 7 \pm 5 \cdot 7(4)$ & $6 \cdot 4 \pm 1 \cdot 0(4)$ \\
\hline
\end{tabular}

${ }^{*}$ Results significantly different from control: ${ }^{*} \mathrm{p}<0.05, \dagger \mathrm{p}<0.02, \neq \mathrm{p}<0.001$.

8Identifies data for which the control value was inappropriate (see text).

\section{Discussion}

A pronounced cranio-caudal HVA concentration gradient, ${ }^{23}$ together with a large reduction in the HVA content in lumbar fluid of patients with spinal canal blockage, ${ }^{24-27}$ suggests that HVA in the lumbar subarachnoid space is mainly of cerebral origin. Moreover, the highest CSF concentration of this metabolite is found in the lateral ventricles, ${ }^{28}$ so it is likely that HVA originates from the caudate nucleus. Analysis of this region at necropsy has suggested an age-dependent decline in dopamine function $^{29}$ which contrasts with the age-dependent increase in the content of HVA in CSF found in this and other studies. ${ }^{183031}$ This change in CSF HVA is, therefore, likely to be a consequence of either increased egress from brain or reduced outflow from CSF.

The finding of a reduced concentration of HVA in the CSF of histologically verified Alzheimer patients may reflect the increase in ventricular volume that accompanies cerebral atrophy. This is unlikely, since patients with normotensive hydrocephalus have greater than normal concentrations of HVA in the lumbar fluid. ${ }^{32}{ }^{33}$ An alternative explanation is that there is an alteration in the activity of dopamine neurons in the caudate nucleus of Alzheimer patients. Necropsy analysis supports this view, with a reported $38 \%$ decline in the concentration of HVA in this region in Alzheimer's dementia, ${ }^{9}$ but without a change in dopamine content. Investigation of patients with Parkinson's disease, ${ }^{35}$ suggest that such an alteration is unlikely to have a clinical effect.

5-HIAA also displays a cranio-caudal concentration gradient ${ }^{23}$ although analysis of patients with interrupted CSF flow reveals no more than a slight reduction in 5-HIAA content of lumbar fluid. ${ }^{24-27}$ Thus it is unclear whether the present finding of reduced 5-HIAA content in the CSF of Alzheimer's dementia patients is related to a cerebral or spinal cord dysfunction. Spinal cord pathology is not a feature of Alzheimer's dementia so it seems reasonable to attribute the reduction in the content of 5-HIAA in CSF to cerebral changes.

Diminished noradrenergic neuronal function in the neocortex ${ }^{4-7}$ together with extensive cell loss in the locus coeruleus ${ }^{61011}$ suggest an involvement of ascending noradrenergic pathways in the pathogenesis of Alzheimer's dementia. The absence of a change in the content of MHPG in the CSF of Alzheimer patients presented here indicates a sparing of descending coeruleo-spinal neurons. ${ }^{273637}$ in this disorder. The pathogenesis of Alzheimer's dementia is, therefore, likely to differ from Korsakoff's psychosis where reduced CSF concentrations of MHPG, together with a correlation between this metabolite and amnesic symptoms, have been reported..$^{12}$ Such selectivity in Alzheimer's dementia suggests that neocortical noradrenergic dysfunction is not primarily due to an intrinsic defect in the locus coeruleus.

The authors thank Drs M Haltia, A Paetau, and DMA Mann for help in collection and classification of the samples.

\section{References}

' Marsden CD, The diagnosis of dementia. In: Isaacs B, Post F, eds. Studies in Geriatric Psychiatry. Chichester: John Wiley and Sons, 1978;99-118.

2 Tomlinson BE. Plaques, tangles and Alzheimer's disease. Psychol Med 1982;12:449-59.

${ }^{3}$ Sims NR, Bowen DM, Allen SJ et al. Presynaptic cholinergic dysfunction in patients with dementia. $J$ Neurochem 1983;40:503-9.

${ }^{4}$ Berger B, Tassin JP, Runcurel G, Bianc G. Catecholaminergic innervation of the human cerebral cortex in presenile dementia. Histochemical and biochemical studies. In: Usdin E, ed. Enzymes and Neurotransmitters in Mental Disease. Chichester: John Wiley \& Sons, 1980;317-27.

${ }^{5}$ Cross AJ, Crow TJ, Perry EK, Blessed G, Tomlinson BE. Reduced dopamine-hydroxylase activity in 
Alzheimer's disease. $\mathrm{Br}$ Med J 1981;282:93-94.

${ }^{6}$ Perry EK, Tomlinson BE, Blessed G, Perry RH, Cross AJ, Crow TJ. Neuropathological and biochemical observations on the noradrenergic system in Alzheimer's disease. J Neurol Sci 1981;51:279-87.

${ }^{7}$ Benton JS, Bowen DM, Allen SJ, et al. Alzheimer's disease as a disorder of the isodendritic core. Lancet 1982;ii:456.

${ }^{8}$ Bowen DM, Allen SJ, Benton JS, et al. Biochemical assessment of serotonergic and cholinergic dysfunction and cerebral atrophy in Alzheimer's disease. $J$ Neurochem 1983;41:266-72.

9 Adolfsson R, Gottfries CG, Roos BE, Winblad B. Changes in the brain catecholamines in patients with dementia of Alzheimer type. $\mathrm{Br} J$ Psychiatry 1979;135: 216-23.

${ }^{10}$ Mann DMA, Lincoln J, Yates PO, Stamp JE, Toper S. Changes in the monoamine containing neurones of the human CNS in senile dementia. Br J Psychiatry 1980;136:533-41.

" Bondareff W, Mountjoy CQ, Roth M. Selective loss of neurones of origin of adrenergic projection to cerebral cortex (nucleus locus coeruleus) in senile dementia. Lancet 1981;i:783-4.

${ }^{12}$ McEntee WJ, Mair RG. Memory impairment in Korsakoff's psychosis: a correlation with brain noradrenergic activity. Science 1978;202:904-5.

${ }^{13}$ Gottfries CG, Gottfries I, Roos BE. Homovanillic acid and 5-hydroxyindoleacetic acid in the cerebrospinal fluid of patients with senile dementia, presenile dementia and Parkinsonism. $J$ Neurochem 1969; 16: 1341-5.

14 Gottfries CG, Gottfries I, Roos BE. Homovanillic acid and 5-hydroxyindoacetic acid in cerebrospinal fluid related to rated mental and motor impairment in senile and presenile dementia. Acta Psychiat Scandinav 1970;46:99-105.

is Gottfries CG, Roos BE. Acid monoamine metabolites in cerebrospinal fluid from patients with presenile dementia (Alzheimer's disease). Acta Psychiat Scand 1973;49:257-63.

${ }^{16}$ Gottfries CG, Kjallquist A, Ponten U, Roos BE, Sundberg G. Cerebrospinal fluid $\mathrm{pH}$, monoamine and glycolytic metabolites in Alzheimer's disease. $\mathrm{Br} J$ Psychiatry 1974;124:280-7.

${ }^{17}$ Soininen H, MacDonald E, Rekonen M, Riekkinen PJ. Homovanillic acid and 5-hydroxyindoleacetic acid levels in cerebrosphinal fluid of patients with senile dementia of Alzheimer type. Acta Neurol Scand 1981;64:101-7.

${ }^{18}$ Bareggi SR, Franceschi M, Bonini L, Zecca L, Smirne S. Decreased CSF concentration of homovanillic acid and $\gamma$-aminobutyric acid in Alzheimer's disease. Arch Neurol 1982;39:709-12.

${ }^{19}$ Parkes JD, Marsden CD, Rees JE et al. Parkinson's disease, cerebral arteriosclerosis and senile dementia. $Q J$ Med 1974;43:49-61.

${ }^{20}$ Mann JJ, Stanley M, Neophylides A, DeLeon MJ, Ferris $\mathrm{SH}$, Gershon $\mathrm{S}$. Central amine metabolism in Alzheimer's disease: in vivo relationship to cognitive defect. Neurobiol Aging 1981;2:57-60.

${ }^{21}$ Wood PL, Etienne P, Gauthier LS, Cajal S, Nair NPV. Reduced lumbar CSF somatostatin in Alzheimer's disease. Life Sci 1982;31:2073-9.

${ }^{22}$ Bowen DM, Sims NR, Benton JS, Curzon G, Davison AN, Neary D, Thomas DJ. Treatment of Alzheimer's disease: A cautionary note. $N$ Engl $J$ Med 1981;305: 1016.

${ }^{23}$ Sjostrom R, Ekstedt J, Anggard E. Concentration gradients of mono amine metabolites in human cerebrospinal fluid. J Neurol Neurosurg Psychiatry 1975;38:666-8.

${ }^{24}$ Post RM, Goodwin FK, Gordon E, Watkin DM. Amine metabolites in human cerebrospinal fluid: effects of cord transection and spinal fluid block. Science $1973 ; 179 ; 897-9$.

${ }^{25}$ Curzon G, Gumpert EJW, Sharpe DM. Amine metabolites in the lumbar cerebrospinal fluid of human with restricted flow of cerebrospinal fluid. Nature New Biol 1971;231:189-91.

${ }^{26}$ Young SN, Lal S, Martin JB, Fond RM, Sourkes TL. 5-hydroxyindoleacetic acid, homovanillic acid and tryptophan levels in CSF above and below a complete block of CSF flow. Psychiat Neurol Neurochir(Amst) 1973;76:439-44.

${ }^{27}$ Garelis E, Sourkes TL. Sites of origin in the central nervous system of monoamine metabolites measured in human cerebrospinal fluid. J Neurol Neurosurg Psychiatry 1973;4:625-9.

${ }^{28}$ Wood JH. Sites of origin and cerebrosphinal fluid concentration gradients. In Wood JH, ed. Neurobiology of Cerebrospinal Fluid. New York: Plenum Press, 1980;53-62.

${ }^{29}$ McGeer PL, McGeer EG. Neurotransmitters in the ageing brain. In: Davison AN, Thompson RHS, eds. The Molecular Basis of Neuropathology. London: Edward-Arnold, 1981;649-66.

${ }^{30}$ Gottfries CG, Gottfries I, Johansson B, Olsson R, Persson $T$, Roos BE. Acid monoamine metabolites in human cerebrospinal fluid and their relation to age and sex. Neuropharmacol 1971;10:665-71.

${ }^{31}$ Bowers MB, Gerbade FA. Relationship of monoamine metabolites in human cerebrospinal fluid with age Nature 1968;219:1256-7.

${ }^{32}$ Coblentz JM, Mattis S, Zingesser LH, Kasoff SS, Wisniewski HM, Katzman R. Presenile dementia. Arch Neurol 1973;29:299-308.

${ }^{33}$ Anderson H, Roos BE. Acidic monoamine metabolites in the cerebrospinal fluid of children with hydrocephalus. Acta Neurologica Scand 1965;Suppl 13: $149-51$.

${ }^{34}$ Yates CM, Allison Y, Simpson J, Maloney AGF, Gorden A. Dopamine in Alzheimer's disease and senile dementia. Lancet 1979;ii:851-2.

${ }^{35}$ Hornykiewicz $\mathrm{O}$. Dopamine changes in the aging human brain: functional considerations. In: Agnoli A, Crepaldi G, Spano PF, Trabacchi M, eds. Aging Brain and Ergot Alkaloids. (Aging Vol. 23). New York: Raven Press, 1983;9-14.

${ }^{36}$ Ader JP, Posterma F, Kork J. Contribution of the locus coeruleus to the adrenergic innervations in the rat spinal cord. J Neural Trans 1979;44:159-73.

${ }^{37}$ Commisiong JW, Hellstrom SU, Neff NH. A noradrenergic projection from locus coeruleus to spinal ventral columns: histochemical and biochemical evidence. Brain Res 1978;148:207-13. 